\title{
Pink mold rot of muskmelon and tomato fruits and trichothecin production by Trichothecium roseum
}

\author{
H. Takahashi*1, S. Uematsu*2, T. Oizumi*2, E. Mori*3, \\ S. YANAGIHORI*3 and M. ICHINOE*4
}

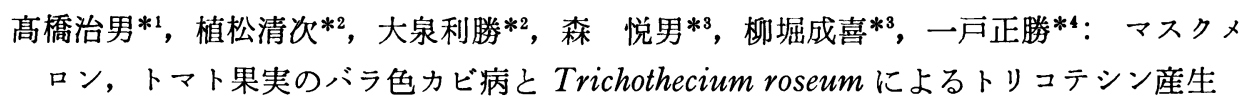

\begin{abstract}
Summary
Trichothecium roseum causes pink mold rot of muskmelons and tomatoes cultivated in greenhouses, and also produces trichothecin, a 12,13-epoxytrichothecene. To clarify the pathogenicity and trichothecin production of $T$. roseum, mycological examination was carried out in 8 greenhouses in Chiba Prefecture. The contamination of muskmelon and tomato fruits with trichothecin was also examined. Trichothecium roseum was isolated from almost all of the moldy or discolored muskmelon and tomato fruits, as well as tomato stem dumped near the greenhouse. The fungus was found in the air of a greenhouse in which many moldy tomato fruits were present, but in none of the soil samples from the greenhouses tested. In an inoculation test, $T$. roseum isolated from muskmelon and tomato invaded and decayed the flesh of matured muskmelons. Moreover, almost all the isolates of $T$. roseum tested produced trichothecin on Czapek-Dox broth supplemented with $0.2 \%$ corn steep liquor cultured for 21 days at $25^{\circ} \mathrm{C}$. Trichothecin was detected in moldy muskmelon and tomato fruits collected in the greenhouses.
\end{abstract}

Muskmelon (Cucumis melo L. var. reliculatus) and tomato (Lycopersicon esculentum) are commonly cultivated in greenhouses in Chiba Prefecture, Japan. The fruits are sometimes infected and spoiled by pathogenic fungi such as Trichothecium roseum (Pers.) Link ${ }^{1,2)}$ and Fusarium spp., ${ }^{3,4}$. Trichothecium roseum invades the fruits through injuries and causes pink mold rot. This fungus is a common soil inhabitant and its conidia borne on the infected plant and fruits are probably dispersed by air currents, irrigation water and insects ${ }^{5}$. It produces trichothecin ${ }^{6)}(\mathrm{TCN})$, a member of 12,13-epoxytrichothecenes which is known as a potent antifungal chemical ${ }^{6,7)}$ as well as an effective agent against mammalian cells ${ }^{7)}$.

An outbreak of this mold disease in muskmelon fruit was found from June to August 1993, when the prevailing weather was relatively cool and damp. Previous reports ${ }^{8,9)}$ have

*1 Public Health Laboratory of Chiba Prefecture (666-2 Nitona-cho Chuou-ku Chiba City, Chiba 260) 千葉県衛生研究所 (T260 千葉市中央区更戸名町 666-2)

*2 Chiba Horticultural Experiment Station (1762 Yamamoto Tateyama City, Chiba 294)

千葉県暖地園芸試験場（干294 館山市山本 1762）

*3 Public Health Research Institute of Kawasaki City (5-13-10 Osima Kawasaki-ku Kawasaki City, Kanagawa 210)

川崎市衛生研究所（广210 川崎市川崎区大島 5-13-10）

*4 Department of Domestic Sciences, Tokyo Kasei University (1-18-1 Kaga Itabashi-ku Tokyo, 173) 東京家政大学家政学部（干173 東京都板橋区加賀 1-18-1） 
shown that the fungus grows well between $20^{\circ}$ and $23^{\circ} \mathrm{C}$ and under excessive humidity.

We carried out a mycotoxicological investigation on muskmelon and tomato fruits in greenhouses.

\section{Materials and Methods}

\section{Mycological examination}

1) Muskmelon and tomato fruits, and dumped stems of tomato

Twenty moldy and 9 discolored muskmelon fruits were collected from 6 greenhouses in Chiba Prefecture in 1993. Four moldy tomato fruits from one greenhouse and a tomato stem from a dump site near the greenhouse were also examined. Cuts of damaged portions of the fruits and the stem were placed on water agar plates or Dichloran Rose Bengal Chloramphenicol (DRBC) agar (Oxoid, England) plates. The plates were incubated at $25^{\circ} \mathrm{C}$ for for 7 days. Dichloran was added to restrict the growth of the fungi such as Trichoderma and Rhizopus spp. which spread rapidly and often prevent or hinder the development of $T$. roseum on the plate. Developed fungal colonies were transferred to potatodextrose agar (PDA) plates for identification.

2) Air-borne and soil-borne fungi in greenhouses

Air-borne fungi in 8 greenhouses were collected with an air sampler (RCS type, Biotest, Germany) using an agar strip of HS medium (Biotest, Germany) attached for counting fungi. The sampler was operated for $30 \mathrm{sec}$. $(20 \mathrm{l})$ and $1 \mathrm{~min}$. (40 l) at the height of $1.5 \mathrm{~m}$ from the ground at 2 to 3 points in each greenhouse. The strips were incubated for 7 days at $25^{\circ} \mathrm{C}$. Developed colonies resembling to T. roseum were transferred to PDA plates for identification.

Soil-borne fungi, meanwhile, were examined by the dilution plate and plant debris techniques. Soil samples of 200 to $300 \mathrm{~g}$ were dried in a refrigerator for 2 to 3 days and passed through a screen having $4 \mathrm{~mm}, 0.935 \mathrm{~mm}, 500 \mu \mathrm{m}$ and $340 \mu \mathrm{m}$ mesh, in that order. Ten $\mathrm{g}$ of soil passed through the screen was diluted with $90 \mathrm{ml}$ of sterile $0.1 \%$ peptone water, and a $0.5 \mathrm{ml}$ portion of the diluent was placed onto $\mathrm{DRBC}$ agar plate. Pieces of plant debris on the last screen were collected after washing under running tap water. Fifty or 100 pieces of the debris were placed on DRBC agar plates. These plates were incubated at $25^{\circ} \mathrm{C}$ for 7 days. The developed colonies were transferred to PDA plates for identification, when necessary.

\section{Pathogenicity of fungal isolates to muskmelon fruit}

Six isolates of $T$. roseum isolated from muskmelon (4) and tomato (2) were studied for pathogenicity. The pathogenicity test was carried out by inoculating a culture disk of PDA of each isolate into holes ( $3 \mathrm{~mm}$ in diameter, $5 \mathrm{~mm}$ in depth) previously made on matured muskmelons. The experiments were carried out with three replications per each isolate. The culture disks were also inoculated to another matured muskmelon without holes as a control. In addition, the PDA medium disk was inserted into a hole as another control. All inoculation sites were covered with masking tape and these melon fruits were incubated for 6 days at room temperature. The diameters of portion on the fruits rotted by fungal infection were measured as an index of pathogenic activity. 


\section{Production of trichotecin by $T$. roseum isolates}

Seventeen isolates of $T$. roseum from different sources; muskmelon (12), tomato (4), and and air in tomato greenhouse (1) were grown on PDA slants for 7 days at $25^{\circ} \mathrm{C}$ and then were inoculated into $100 \mathrm{ml}$ of Czapek-Dox broth supplemented with $0.2 \%$ corn steep liquor (Wako, Japan) in a $500 \mathrm{ml}$ volume Fernbach flask. After incubation for 21 days at $25^{\circ} \mathrm{C}$, the culture broth was filtered and the filtrate was shaken twice with $100 \mathrm{ml}$ of ethyl acetate. The combined ethyl acetate layers were evaporated to dryness under vacuo. The extracts were dissolved in $200 \mu \mathrm{l}$ of benzene: acetone $(1: 1, \mathrm{~V} / \mathrm{V})$. The samples and the authentic TCN standard (Sigma, USA) solution ( 25 and $50 \mu \mathrm{g}$ in ethanol) were spotted on a precoated thin-layer chromatography (TIC) plate (Kieselgel 60, no. 5721 Merck, Germany). The plate was developed with the solvent systems; benzene: acetone $(10: 1, \mathrm{~V} / \mathrm{V})$ and chloroform: ethyl acetate $(9: 1, V / V)^{10}$. The TCN from the extracts and the standard were visualized by charring with a mixture solution of conc. sulfuric acid: abs. ethanol $(1: 1, \mathrm{~V} / \mathrm{V})$. The Rf value of TCN from the extract was compared with that of standard TCN for qualitative analysis. Next, the TCN detected in the extracts was confirmed by two-dimensional TLC with the developing solvent, benzene: acetone $(10: 1, \mathrm{~V} / \mathrm{V})$ followed by chloroform: ethyl acetate $(9: 1, \mathrm{~V} / \mathrm{V})$.

\section{Detection of TCN in moldy fruits}

About $200 \mathrm{~g}$ of moldy muskmelon or tomato fruits were homogenized in $200 \mathrm{ml}$ of acetonitrile: water $(3: 1, \mathrm{~V} / \mathrm{V})$ with a whirling blender for $6 \mathrm{~min}$. The homogenate was passed through a filter paper and $200 \mathrm{ml}$ of extract solution was obtained. After defatting with $100 \mathrm{ml}$ of $\mathrm{n}$-hexane, the solution was re-extracted twice with $200 \mathrm{ml}$ of chloroform. The combined chloroform layers were evaporated to dryness. The TCN detected in the extracts was confirmed by two-dimensional TLC in the manner described above. In addition, the toxin was semiquantitatively estimated by densitometrical assay with a computer-assisted imaging system (Bio-1d, Ver. 5.03, Vilber Lourmat, France).

\section{Results and Discussion}

\section{Mycological examination}

1) Muskmelon and tomato fruits, and dumped tomato stem

In the muskmelon fruit samples, $T$. roseum was isolated from all the discolored samples, or about $86 \%$ of all the samples, as shown in Table 1 . The fungus was also found in $75 \%$ of the tomato fruit samples although a limited number of the samples were tested. Fusarium spp. including $F$. semitectum and $F$. avenaceum were isolated from the muskmelon samples along with Phomopsis sp. and Acremonium sp. From the dumped tomato stem close to the muskmelon-cultivated greenhouse, $T$. roseum was isolated in abundance (data not shown). In addition, moldy muskmelon and tomato fruits infected with $T$. roseum were frequently observed in the dump sites near the greenhouses.

2) Air-borne and soil-borne fungi

Table 2 shows air-borne fungi and soil-borne fungi associated with plant debris in greenhouses No. 1 to No. 3 of the 8 greenhouses tested. Trichothecium roseum was not found in 
Table 1. Isolation of fungi from moldy or discolored fruit samples of muskmelon and tomato in greenhouses of Chiba Prefecture in 1993.

\begin{tabular}{lccc}
\hline \multirow{2}{*}{ Fruit and Fungus } & \multicolumn{3}{c}{ No. of fungus-detected fruits/No. of tested fruit } \\
\cline { 2 - 4 } & Moldy fruit & Discolored fruit & Total (\%) \\
\hline Muskmelon & & & \\
T. roseum $*$ & $14 / 18$ & $9 / 9$ & $23 / 27(85.1)$ \\
Fusarium spp. & $3 / 18$ & $0 / 9$ & $3 / 27(11.1)$ \\
Phomopsis sp. & $1 / 18$ & - & $1 / 27$ \\
Acremonium sp. & $1 / 18$ & - & $1 / 27$ \\
Tomato & & & $3 / 4(75.0)$ \\
T. roseum & $3 / 4$ & - & \\
\hline
\end{tabular}

Table 2. Air-borne and soil-borne fungi in a muskmelon greenhouse in Chiba Prefecture in 1993.

\begin{tabular}{|c|c|c|c|c|}
\hline \multirow{2}{*}{$\begin{array}{c}\text { Greenhouse*1 No. and } \\
\text { Fungus }\end{array}$} & \multicolumn{4}{|c|}{ Frequency $(\%)$} \\
\hline & \multicolumn{2}{|c|}{ Air-borne fungus } & \multicolumn{2}{|c|}{$\begin{array}{l}\text { Soil-borne fungus*2 } \\
\text { (Plant debris tech.) }\end{array}$} \\
\hline \multicolumn{5}{|l|}{ No. 1 greenhouse } \\
\hline Fusarium & 80.0 & 32.4 & Trichoderma & 100.0 \\
\hline Cladosporium & 20.0 & 61.8 & Fusarium & 58.8 \\
\hline Penicillium & -*3 & 2.9 & Cephaliophora & 8.0 \\
\hline Phoma & - & 2.9 & & \\
\hline No. of total colonies & 20 & 34 & & \\
\hline \multicolumn{5}{|l|}{ No. 2 greenhouse } \\
\hline Fusarium & 78.3 & 51.1 & Penicillium & 96.0 \\
\hline Cladosporium & 21.7 & 38.3 & Mucor & 66.0 \\
\hline Stachybotrys & - & 4.3 & Syncephalastrum & 34.0 \\
\hline Ulocladium & - & 2.1 & Cunninghamella & 14.0 \\
\hline Cunninghame 11a & - & 2.1 & Aspergillus fumigatus & 8.0 \\
\hline Alternaria & - & 2.1 & Rhizopus & 2.0 \\
\hline No. of total colonies & 23 & 47 & & \\
\hline \multicolumn{5}{|l|}{ No. 3 greenhouse } \\
\hline Cladosporium & 50.0 & 22.2 & Aspergillus flavus & 98.0 \\
\hline Fusarium & 33.3 & 55.6 & Cephaliophora & 14.0 \\
\hline Alternaria & 16.7 & 11.1 & Mucor & 12.0 \\
\hline \multirow[t]{2}{*}{ Paecilomyces } & - & 11.1 & Aspergillus terreus & 8.0 \\
\hline & & & Rhizopus & 2.0 \\
\hline No. of total colonies & 6 & 9 & & \\
\hline
\end{tabular}

*1 Muskmelon was cultivated on soil on a plate separated from the ground.

*2 Detected by plant debris (50 pieces) technique.

*3 Not detected.

any of these 3 greenhouses. The predominant fungi in the air of the greenhouses were Cladosporium and Fusarium. In our study, T. roseum ( 2 isolates) was found only at the 201 sampling only in the air of one greenhouse (No. 8) in which many moldy tomato fruits 
were present (data not shown).

Consequently, $T$. roseum was not isolated from any soil sample by either of the techniques (dilution plate and plant debris techniques) used in this study. The soil used for cultivation of muskmelon in a greenhouse is generally sterilized before planting. Trichothecium roseum also was not isolated from the soil in the dump site, whereas Penicillium and Fusarium spp. were abundant (data not shown).

\section{Pathogenicity of the fungal isolates to muskmelon fruit}

All the 6 isolates of $T$. roseum, including 2 isolates from tomato fruits produced disease lesions in the flesh of muskmelons with wounds (holes). But no fungal damage was observed on the fruits without wounds or the control fruit with the medium plate of PDA inserted into the holes, as shown in Table 3. Each inoculum was re-isolated from the rotted portion of the infected fruits. These results (Tables 1 and 3) suggested that T. roseum is a dominant rotting fungus in muskmelons at harvest time in greenhouses of Chiba Prefecture. The muskmelon forms a net on the coat of the fruit, which is a wounded cork but generally heals up during maturing. Ohsawa et al. ${ }^{11)}$ concluded from their inoculation test that Phomopsis spp., pathogens to muskmelon, could infect the fruits before harvest, probably during net formation stage. The wounded portion must also be attacked by $T$. roseum, because it is well known that pink mold rot of muskmelon is usually found during the same stage.

Trichothecium roseum isolates from tomato fruits also exhibited pathogenicity to the muskmelon fruit. The conidia of $T$. roseum on the diseased muskmelon and tomato fruits and tomato stem from the dump site might be dispersed to the greenhouse by air currents, but further mycological experiments are required to clarify on this point.

\section{Production of TCN by $T$. roseum isolates}

Sixteen of 17 tested isolates from muskmelon and tomato fruits and the air in the tomato greenhouse produced TCN on a Czapek-Dox broth medium supplemented with corn steep liquor (Table 4). TCN in the culture extracts was qualitatively determined by two-dimen-

Table 3. Pathogenicity of $T$. roseum isolated from muskmelon and tomato on muskmelon fruit.

\begin{tabular}{clcc}
\hline Isolate & Source & \multicolumn{2}{c}{$\begin{array}{c}\text { Diameter of lesion }(\mathrm{cm})^{* 1} \\
\text { Inoculating } \\
\text { without wound }\end{array}$} \\
\hline T. roseum & Muskmelon & 2.0 & 0.0 \\
TR 41*3 & Muskmelon & 1.8 & 0.0 \\
TR 61 & Muskmelon & 1.9 & 0.0 \\
TR 171 & Muskmelon & 2.0 & 0.0 \\
TR 181 & Tomato & 1.7 & 0.0 \\
TR 9303-2 & Tomato & 2.4 & 0.0 \\
TR-S-2 & & 0.0 & 0.0 \\
Control*2 & & & \\
\hline
\end{tabular}

*1 Average value in 3 replications of the rotted portion on the muskmelon fruit.

*2 Inserting a PDA disk without culture as a control.

*3 Strain no. in our laboratory. 
Table 4. Production of trichothecin by $T$. roseum isolates from the muskmelon and tomato fruits.

\begin{tabular}{lcc}
\hline Source & No. of isolate tested & $\begin{array}{c}\text { No. of trichothecin-producing } \\
\text { isolate }\end{array}$ \\
\hline Muskmelon & 12 & 11 \\
Tomato & 4 & 4 \\
Air* & 1 & 1 \\
Total & 17 & $16(94.4 \%)$ \\
\hline
\end{tabular}

* Isolate from the air in the tomato greenhouse.

sional TLC. As for the TCN production, Ishii et al. ${ }^{12)}$ and Sorenson et al. ${ }^{10)}$ have demonstrated that all the isolates of $T$. roseum which they tested produced TCN on wheat and liquid media. These results suggested that $T$. roseum is a consistent producer of TCN.

\section{TCN contamination in moldy tomato and muskmelon fruits}

The detection of TCN in the muskmelon and tomato fruits which $T$. roseum naturally infected in a greenhouse was also confirmed by two-dimensional TLC, as shown in Fig. 1. These results suggest that $T$. roseum produces the mycotoxin in these fruits when environmental conditions are suitable for fungal growth and toxin synthesis. The amounts of TCN in extremely moldy melon and tomato fruits were 13.2 and $21.4 \mathrm{ppm}$, respectively. TCN contamination has previously been found in apples ${ }^{13)}$, pears ${ }^{13)}$, anise fruits $^{14}$ and whea ${ }^{12)}$ in addition to muskmelon and tomato fruits in this study. The diseased flesh of

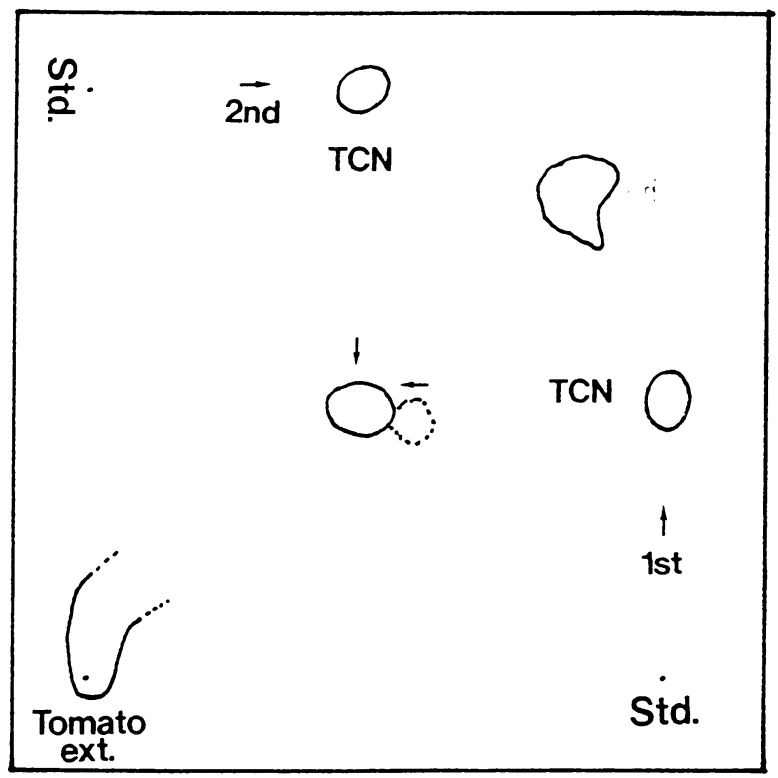

Fig. 1. Detection of $\mathrm{TCN}$ in tomato fruit naturally infected by $T$. roseum in the greenhouse. The toxin was confirmed by two-dimensional thin layer chromatography with the solvent systems: benzene: acetone (10:1, first), chloroform: ethyl acetate (9: 1 , second). 
muskmelon and tomato is slightly brown in color and its taste is extremely bitter ${ }^{1,2)}$. The lethan does of TCN was $250 \mathrm{mg} / \mathrm{kg}$ by subcutaneous administration in rats and intravenops administration in mice ${ }^{15}$.

Acknowledgments We wish to thank Dr. T. Takeuchi of Chiba Prefectural Agricultural Experiment Station for the supply of $T$. roseum isolates.

\section{References}

1) Hirai, S., Amamiya, R., Hirano, K., Iida, K., Sato, K.: Ann. Phytopath. Soc. Japan, 52, 145 (1986) (Abstract).

2) Takeuchi, T. and Suzuki, H.: Ann. Phytopath. Soc. Japan, 59, 730 (1993) (Abstract).

3) Carter, W. W.: Plant Dis. Rep., 63, 1080 (1979).

4) Ohsawa, T., Matsuo, T.: Ann. Phytopath. Soc. Japan, 51, 333 (1985).

5) Snowdon, A. L.: "A Colour Atlas of Post-harvest, Disease \& Disorders of Fruits \& Vegetables" Vol. 2 Vegetables. pp. 40-41 and p. 78, (1991): Wolfe Scientific, London.

6) Freeman, G. G., Morrison, R. I.: Nature (London) 162, 30 (1949).

7) Bamburg, J. R., Strong, F. M.: “Microbial Toxins, vol. 7: 12,13-epoxytrichothecens" (ed. Kadis, S., Ciegler, A., Aj1, S. J.) (1971), Academic Press, New York.

8) Kendrick, W. B., Cole, G. T.: Can. J. Bot. 47, 345 (1969).

9) Matsunami, Y., Tanda, S., Ohta, T.: Nougakushuhou, 18, 15 (1972).

10) Sorenson, W. G., Sneller, M. R., Larsh, H. W.: Appl. Environ. Microbiol., 29, 653 (1975).

11) Ohsawa, T., Kobayashi, T.: Ann. Phytopath. Soc. Japan, 55, 410 (1989).

12) Ishii, K., Kobayashi, J., Ueno, Y., Ichinoe, M.: Appl. Environ. Microbiol., 52, 331 (1986).

13) Príbera, A., Lácók, P.: Pol'nohospodrastvo, 22, 278 (1976).

14) Ghosal, S., Chakrabarti, D. K., Srivastava, A. K., Srivastava, R. S.: J. Agr. Food Chem., 30, 106 (1982).

15) Freeman, C. D.: J. Gen. Microbiol., 12, 213 (1956). 